\title{
Optimal Apartment Cleaning by Harried College Students: A Game-Theoretic Analysis
}

\author{
Amitrajeet A. Batabyal \\ Department of Economics, Rochester Institute of Technology, Rochester, NY, USA \\ Email: aabgsh@rit.edu
}

How to cite this paper: Batabyal, A.A. (2017) Optimal Apartment Cleaning by Harried College Students: A Game-Theoretic Analysis. Theoretical Economics Letters, 7, 1255-1260.

https://doi.org/10.4236/tel.2017.75085

Received: June 17, 2017

Accepted: July 29, 2017

Published: August 1, 2017

Copyright $\odot 2017$ by author and Scientific Research Publishing Inc. This work is licensed under the Creative Commons Attribution International License (CC BY 4.0).

http://creativecommons.org/licenses/by/4.0/

\begin{abstract}
In this note, we use a simple game model to analyze the optimal cleanup of an apartment that is shared by $n \in \mathbb{N}$ college students who are pressed for time. From an individual standpoint, these students dislike cleaning. However, they also prefer a clean apartment to a dirty one. Hence, for any student $i$, where $i=1, \cdots, n$, this student's utility is the total number of hours spent by all the $n$ students cleaning less a threshold $d$ times the hours spent cleaning by himself. In this setting, we first determine the Nash equilibrium cleanup times when the threshold $d$ is less than unity. Second, we find the Nash equilibrium cleanup times when the threshold $d$ is greater than unity. Finally, for specific values of $n$ and the threshold $d$, we investigate whether the second Nash equilibrium is Pareto efficient.
\end{abstract}

\section{Keywords}

Apartment, Cleanup, College Student, Nash Equilibrium, Static Game

\section{Introduction}

College students in the United States typically spend their first (freshman) and sometimes their second (sophomore) year living in dormitories. However, once they pass this stage of their college careers, these same students frequently move to both on- and off-campus apartments. In some universities, quite apart from a desire for greater independence on the part of the students, such a move is required by the fact that the pertinent university is able to guarantee housing only to a fraction of all enrolled students. ${ }^{1}$

In most private and public colleges and universities in the United States, dormitory living generally does not entail any serious cleaning activities on the part

${ }^{1}$ See Tietjen [1] for more details on this point and for a listing of the dormitory capacities of a whole host of colleges and universities in the United States. 
of the students because of the routine presence of custodial staff. However, this state of affairs clearly changes once students move into apartments. In this new living arrangement, the cleanliness of a shared apartment depends fundamentally on the effort exerted by the individual students in keeping this apartment clean.

The available evidence clearly demonstrates that students sharing apartments routinely get into conflicts because of, inter alia, their heterogeneous preferences for cleanliness. ${ }^{2}$ Therefore, it is no surprise that stories about the widespread disadvantages of living either with "neatfreaks" or with "slobs" are legion in American popular culture. College and university departments of residential life and housing commonly advise students about the ways in which they can avoid conflicts stemming from misunderstood or ill-defined apartment cleaning chores. Hence, the problem of the appropriate division of responsibilities for cleaning a shared apartment is both endemic and relevant.

This notwithstanding, to the best of our knowledge, economists have paid no attention to this apartment cleanup problem that we have just alluded to. ${ }^{3}$ Given this lacuna in the literature, the purpose and the main contribution of this note are to use a simple game model to analyze the optimal cleanup of an apartment that is shared by $n \in \mathbb{N}$ college students who are pressed for time. From an individual standpoint, these students dislike cleaning. However, they also prefer a clean apartment to a dirty one. Therefore, for any student $i$, where $i=1, \cdots, n$, this student's utility is the total number of hours spent by all the $n$ students cleaning less a threshold $d$ times the hours spent cleaning by himself. Section 2.1 describes the static game of complete information ${ }^{4}$ model we employ to conduct the analysis. Section 2.2 ascertains the Nash equilibrium cleanup times when the threshold $d$ is less than unity. Section 2.3 determines the Nash equilibrium cleanup times when the threshold $d$ is greater than unity. In Section 2.4, for specific values of $n$ and the threshold $d$, we investigate whether the Nash equilibrium we have determined in Section 2.3 is Pareto efficient. Section 3 concludes and then offers three suggestions for extending the research described in this note.

\section{Analysis}

\subsection{The Game Model}

Our basic hypothesis in this note is that the theory of static games of complete information can be used to model and shed light on the problem of optimal apartment cleaning by harried college students. To this end, consider a scenario in which $n$ college students share an apartment. Each of these $n$ students has a fixed number of hours available to him that can be used to clean this apartment. Let us denote the fixed endowment of time that is measured in hours by $H>0$.

${ }^{2}$ See Ogletree et al. [2] [3] and Yadegaran [4] [5] for a more detailed corroboration of this claim. ${ }^{3} \mathrm{We}$ emphasize that as best as we can tell, there is no game-theoretic literature on the subject of this note.

${ }^{4}$ Many contemporary textbooks such as Tadelis [6] contain lucid discussions of static games of complete information. 
What makes the apartment cleanup problem interesting is the fact that even though each student, from an individual perspective, dislikes cleaning, collectively, these same students prefer a clean apartment to a dirty one.

The amount of time spent cleaning the apartment by the ith student is denoted by $c_{i}>0$. The threshold $d>0$ is as explained in Section 1. Putting these two pieces of information together, the ith student's utility function is given by

$$
u_{i}\left(c_{1}, c_{2}, \cdots, c_{n}\right)=\sum_{j=1}^{n} c_{j}-d c_{i} .
$$

As written, the ith student's utility is given by the sum of two terms. The first term on the right-hand-side (RHS) of Equation (1) is the positive contribution to utility stemming from the total time devoted to cleaning the apartment by all the students sharing the apartment under study. Here, the numerical weight on the th student's positive contribution is equal to one. The second term on the RHS is the negative contribution to utility arising from the displeasure experienced by the th student from time spent cleaning the apartment by himself. We assume that all the college students simultaneously determine how much time they would like to spend cleaning their apartment. Given this background, our task now is to determine the Nash equilibrium cleanup times when the threshold $d$ is less then unity.

\subsection{The Nash Equilibrium When $d<1$}

We begin by rewriting the ith student's utility function in Equation (1). This gives us

$$
u_{i}\left(c_{1}, c_{2}, \cdots, c_{n}\right)=\sum_{\forall j \neq i} c_{j}+(1-d) c_{i}
$$

Inspecting Equation (2), we see that the ith student's utility function is linear in both his own time spent cleaning up $\left(c_{i}\right)$ and in the cleanup times of this student's remaining $n-1$ apartment mates $\left(c_{j}\right)$. When the threshold $d<1$, every additional amount of time $\tau$ that student $i$ spends cleaning the apartment contributes to his utility by the amount $(1-d) \tau>0$. Put differently, because the ith student's utility function is linear and increasing in his decision variable $c_{i}$, it is optimal to set $c_{i}$ at its upper bound which is $H$. In words, when the threshold $d<1$, it is optimal for any student $i$ to spend all of his available time of $H$ hours to clean the apartment he lives in.

The reader should note that using calculus to maximize the utility function given in Equation (2) by choosing $c_{i}$ does not give the correct answer because, using this approach, we get $d=1$ which is clearly incorrect because we are studying the case where the threshold $d<1$. The reason why calculus misleads is that the optimal solution in this case is not an interior point of the feasible set $[0, H]$. In other words, the unique Nash equilibrium in pure strategies we have found is a corner solution in which it is optimal to set $c_{i}^{*}=H$ for all $i=1, \cdots, n$. What happens to this Nash equilibrium when the threshold $d>1$ ? We now proceed to answer this question. 


\subsection{The Nash Equilibrium When $d>1$}

In this case, every additional amount of time $\tau$ that the th student spends cleaning his apartment contributes to his utility by the amount $(1-d) \tau<0$. Therefore, because of the rationale given in Section 2.2 above, it is now optimal to set the decision variable $c_{i}$ at its lower bound and this means that $c_{i}^{*}=0$ for all $i=1, \cdots, n$. So, once again the unique Nash equilibrium in pure strategies we have found is a corner solution but this solution is at the other corner of the feasible set $[0, H]$. In this equilibrium, none of the students spend any time cleaning the apartment that they are all sharing and hence the utility accruing to all of them is equal to zero. We now proceed to our final task and that is to determine whether the unique Nash equilibrium we have just found is Pareto efficient.

\subsection{Pareto Efficiency}

To illustrate the nature of our findings thus far, let us specialize the discussion to the case where there are five college students who share the apartment under study and hence $n=5$. In addition, suppose that the threshold $d=2$. Now, if the Section 2.3 Nash equilibrium involving no cleanup whatsoever and zero utilities to all the students is Pareto efficient then it should not be possible to improve upon this equilibrium.

To ascertain whether this Nash equilibrium is or is not Pareto efficient, suppose that the apartment landlord, disgusted with how filthy his apartment has become, gives the resident college students the following ultimatum: "Either clean up or be evicted." Faced with possible eviction, the students all increase the amount of time they devote to cleaning up the apartment from $c_{i}=0$ to $c_{i}=1$ for $i=1, \cdots, n$. In this case, substituting $\left(n, d, c_{i}\right)=(5,2,1)$ into the utility function in Equation (2), we see that the ith student's utility now is

$$
u_{i}\left(c_{1}, c_{2}, \cdots, c_{n}\right)=\sum_{\forall j \neq i} c_{j}+(1-d) c_{i}=4 \times 1+(1-2) \times 1=3>0
$$

Equation (3) clearly tells us that the Nash equilibrium in Section 2.3 is not Pareto efficient. In addition, inspecting Equation (3) we see that relative to the Nash equilibrium with no cleanup, the $n$ students sharing the apartment are clearly better off with some $\left(c_{i}=1\right)$ cleanup.

Generalizing the above argument, we see that every time the ith student increases his cleanup time by $\tau>0$ the impact on his utility is negative and equal to $(1-2) \tau=-\tau$. However, this same increase in cleanup raises the utilities of all the other students by $\tau$. Therefore, if each individual student raises the time he devotes to cleaning the apartment by $\tau$ then the gain to each individual student equals his loss. However, this same action on his part increases the gain to all the other students by $\tau$ and the total gain is $n \tau$ which equals $5 \tau$ in this specific case. From this line of reasoning, it should be clear that the Section 2.3 Nash equilibrium can not only be improved upon but that the best outcome arises when every student selects the maximum available time $\left(c_{i}^{*}=H\right)$ to clean the apartment under study. 


\section{Conclusions}

In this note, we used a simple game model to study the optimal cleanup of an apartment that was shared by $n \in \mathbb{N}$ college students who were pressed for time. From an individual perspective, these students disliked cleaning. However, they also all preferred a clean apartment to a dirty one. Hence, for any student $i$, where $i=1, \cdots, n$, this student's utility was the total number of hours spent by all the $n$ students cleaning less a threshold $d$ times the hours spent cleaning by himself. In this setting, we first determined the Nash equilibrium cleanup times when the threshold $d$ was less than unity. Next, we computed the Nash equilibrium cleanup times when the threshold $d$ was greater than unity. Finally, for specific values of $n$ and the threshold $d$, we showed that the Nash equilibrium in the $d>1$ case was not Pareto efficient.

The analysis in this note can be extended in a number of different directions. Here are three examples of the ways in which this might actually be done. First, it would be useful to determine what the theory of social situations discussed in Beladi and Oladi [7] can tell us about optimal apartment cleaning by harried college students. Second, it would be helpful to introduce uncertainty into the model and to study a scenario in which it is not possible to definitively ascertain whether and the extent to which a particular student has fulfilled his apartment cleaning duties. Finally, in an intertemporal setting, it would be helpful to see if any agreement that the harried college students can come up with about establishing who will clean when and for how long, is renegotiation-proof. Studies of apartment cleaning and, more generally, the performance of necessary chores by time constrained college students that incorporate these aspects of the problem into the analysis will provide additional insights into a time allocation problem that has significant economic and social implications for young people.

\section{Acknowledgements}

Batabyal thanks three anonymous reviewers for their helpful comments on a previous version of this note and Cassandra Shellman for her help in formatting the note. In addition, he acknowledges financial support from the Gosnell endowment at RIT. The usual disclaimer applies.

\section{References}

[1] Tietjen, D. (2015) Colleges with the Lowest Dorm Capacities. Forbes, July 31.

[2] Ogletree, S.M., Turner, G.M., Viera, A. and Brunotte, J. (2005) College Living: Issues Related to Housecleaning Attitudes. College Student Journal, 39, 729-733.

[3] Ogletree, S.M., Worthen, J.B., Turner, G.M. and Vickers, V. (2006) Developing an Attitudes toward Housecleaning Scale: Gender Comparisons and Counseling Applications. The Family Journal, 14, 400-407. https://doi.org/10.1177/1066480706289589

[4] Yadegaran, J. (2013) College Roommates: Five Tips for Keeping the Peace. San Jose Mercury News, August 7.

[5] Yadegaran, J. (2013) Seven College Roommate Conflicts-and Solutions. San Jose Mercury News, August 7. 
[6] Tadelis, S. (2013) Game Theory. Princeton University Press, Princeton.

[7] Beladi, H., and Oladi, R. (2006) Strategic Advertising: The Fat-Cat Effect and Stability. Mathematical Social Sciences, 51, 153-161.

https://doi.org/10.1016/j.mathsocsci.2005.08.001

Submit or recommend next manuscript to SCIRP and we will provide best service for you:

Accepting pre-submission inquiries through Email, Facebook, LinkedIn, Twitter, etc. A wide selection of journals (inclusive of 9 subjects, more than 200 journals)

Providing 24-hour high-quality service

User-friendly online submission system

Fair and swift peer-review system

Efficient typesetting and proofreading procedure

Display of the result of downloads and visits, as well as the number of cited articles Maximum dissemination of your research work

Submit your manuscript at: http://papersubmission.scirp.org/

Or contact tel@scirp.org 